\title{
Insights into the Biology of IRES Elements through Riboproteomic Approaches
}

\author{
Almudena Pacheco ${ }^{1,2}$ and Encarnacion Martinez-Salas ${ }^{1}$ \\ ${ }^{1}$ Centro de Biologia Molecular Severo Ochoa, CSIC-UAM, Nicolas Cabrera 1, Cantoblanco, 28049 Madrid, Spain \\ ${ }^{2}$ Fox Chase Cancer Center, 333 Cottman Avenue, Philadelphia, PA 19111-2497, USA
}

Correspondence should be addressed to Encarnacion Martinez-Salas, emartinez@cbm.uam.es

Received 28 July 2009; Accepted 3 December 2009

Academic Editor: Helen J. Cooper

Copyright ( 2010 A. Pacheco and E. Martinez-Salas. This is an open access article distributed under the Creative Commons Attribution License, which permits unrestricted use, distribution, and reproduction in any medium, provided the original work is properly cited.

\begin{abstract}
Translation initiation is a highly regulated process that exerts a strong influence on the posttranscriptional control of gene expression. Two alternative mechanisms govern translation initiation in eukaryotic mRNAs, the cap-dependent initiation mechanism operating in most mRNAs, and the internal ribosome entry site (IRES)-dependent mechanism, first discovered in picornaviruses. IRES elements are highly structured RNA sequences that, in most instances, require specific proteins for recruitment of the translation machinery. Some of these proteins are eukaryotic initiation factors. In addition, RNA-binding proteins (RBPs) play a key role in internal initiation control. RBPs are pivotal regulators of gene expression in response to numerous stresses, including virus infection. This review discusses recent advances on riboproteomic approaches to identify IRES transacting factors (ITAFs) and the relationship between RNA-protein interaction and IRES activity, highlighting the most relevant features on picornavirus and hepatitis $\mathrm{C}$ virus IRESs.
\end{abstract}

\section{Translational Control of Gene Expression}

The composition of the cellular proteome at any given time is tightly regulated. This is achieved by fine-tuning of all the processes governing gene expression, including transcription, splicing, mRNA transport, RNA stability, translation, protein stability and posttranslational modification. All the steps within this cascade of events are subjected to their own specific regulation, and contribute to generate a different composition of the proteome by modifying not only the levels but also the identity of the proteins present in the cell under specific conditions. The components that participate in these regulatory events are often engaged in the formation of macromolecular complexes. Protein-protein as well as RNA-protein interactions allow a compartmentalization of the factors needed to control gene expression. Translational control is a key determinant of the cellular proteome. Translation initiation can modify the proteome by altering the efficiency of translation as well as by enabling the synthesis of different forms of a protein from specific genes.
The process of RNA translation includes a series of sequential steps, known as initiation, elongation, termination and ribosome recycling. Most of translational control is exerted at the initiation step, assisted by specific proteins designated translation initiation factors (eIFs). Translation initiation of most eukaryotic mRNAs commences with $5^{\prime}$ end-dependent recruitment of the $43 \mathrm{~S}$ complex (that is composed of a $40 \mathrm{~S}$ subunit bound to eIF2-GTP/Met-tRNAi, eIF1A, eIF1 and eIF3) by eIF4F recognition of the $\mathrm{m}^{7} \mathrm{GpppN}$ (cap) at the $5^{\prime}$ end of the mRNA. In turn, the eIF4F complex comprises eIF4E that physically binds to the cap, eIF4A that unwinds secondary structures in the $5^{\prime}$ untranslated region (5'UTR) and eIF4G, a scaffold protein that interacts with eIF4E, eIF4A and eIF3. Aided by the helicase activity of eIF4A and its cofactor eIF4B, the $43 \mathrm{~S}$ pre-initiation complex scans in $5^{\prime}$ to $3^{\prime}$ direction until an appropriate initiation codon is encountered. Auxiliary factors, eIF1, eIF2 and eIF5, help to identify the correct AUG start codon, resulting in the formation of the $48 \mathrm{~S}$ complex. eIF5 induces hydrolysis of eIF2-bound GTP, which is recycled to the active form by 
eIF2B (guanine nucleotide exchange factor). The poly(A) tail present in the $3^{\prime} \mathrm{UTR}$ of most mRNAs synergistically stimulates the efficiency of translation through recruitment of poly(A)-binding protein (PABP), enabling its interaction with eIF4F located at the mRNA $5^{\prime}$ end. Finally, eIF5B mediates joining of the $60 \mathrm{~S}$ and $40 \mathrm{~S}$ subunits, generating the $80 \mathrm{~S}$ complex competent for protein synthesis [1].

Translation initiation, particularly in viral mRNAs, can occur by an alternative mechanism driven by internal ribosome entry site (IRES) elements, discovered near 20 years ago in two picornaviruses, encephalomyocarditis virus (EMCV) and poliovirus (PV) $[2,3]$. These elements are cis-acting sequences that form secondary and tertiary RNA structures and recruit the translation machinery to an internal position in the mRNA, bypassing a large number of stable structural elements in the viral 5'UTR [4]. Hence, picornavirus IRESdriven initiation is $5^{\prime}$ end-independent and does not require eIF4E to recruit the $40 \mathrm{~S}$ subunit, in contrast to the capdependent initiation mechanism.

The subsequent discovery of an IRES element in hepatitis $\mathrm{C}$ virus (HCV) RNA that was able to recruit $40 \mathrm{~S}$ ribosomal subunits in the absence of eIF4G represented a major breakthrough in the translation field $[5,6]$. This finding opened the question of how IRESs differing in primary sequence, RNA structure, and factor requirements, perform the same function. Over the last two decades, the process of internal initiation has been found to be more general than originally thought, that is, it operates in other RNA and DNA viruses as well as in cellular mRNAs [7]. In all cases, IRESs direct translation of a subset of proteins when cap-dependent translation is severely compromised [4].

The excellent performance of IRESs, together with the fact that they are active in genetically engineered constructs, has been exploited to study how these diverse RNA elements perform the same function. With the exception of one or more polypyrimidine tracts, no primary sequence conservation neither overall structural similarity is detected between picornavirus and HCV IRESs, strongly suggesting that different strategies may be used to recruit the ribosomal subunits. These strategies could be under the control of a distinct group of proteins specifically interacting with each of these regulatory elements. In this review we discuss recent advances in the identification of IRES auxiliary factors. Understanding the role played by these IRES trans-acting factors (ITAFs) may help to unravel the strategies employed by mRNAs to capture the translation machinery internally.

\section{Internal Initiation of Translation in Picornavirus RNAs}

Translation initiation of all picornavirus RNAs is dependent on the IRES located in the long $5^{\prime}$ UTR (Figure 1(a)). Various structural elements in the $5^{\prime}$ UTR region, which differ among picornavirus genera, control the viral replication cycle in concerted action with the $3^{\prime}$ UTR [8-11]. The IRES region spans about 450 nucleotides immediately upstream of the functional translation start codon of the polyprotein $[2,3$, $12,13]$. Although less than $50 \%$ of primary sequence is conserved between different members of the picornavirus family, the similarity of their secondary structure allows their classification into four types, I to IV. Type I includes enterovirus (EV, PV, HRV), type II, cardiovirus (EMCV) and aphthovirus (foot-and-mouth disease virus, FMDV), type III, is used for hepatitis A virus (HAV), and the HCVlike IRES conforms group IV. The acquisition of a proper structural organization is a key determinant of internal translation initiation driven by picornavirus IRES [14, 15], and all viral IRES in general $[16,17]$. This feature is well illustrated by mutational and structural studies conducted on the central domain (termed 3 or I) of type II IRES (Figure 1(a)). This region is organized as a cruciform structure with phylogenetically conserved structural motifs that are essential for IRES activity $[18,19]$ and determine the tertiary structure of this region [20-23].

Picornavirus IRES-driven translation initiation depends on the recognition of the IRES by specific cellular proteins [4]. IRESs belonging to types I and II require eIF4G, eIF4A, eIF2, eIF3 and ATP, but no eIF4E, eIF1 or eIF1A to assemble $48 \mathrm{~S}$ complexes in a reconstitution assay with purified components $[13,24,25]$. Specific structural motifs in the stem-loops J-K-L (or 4-5) provide the preferential binding site for eIF4G, eIF4B and eIF3 (Figure 1(a)) [2628]. However, interaction of these eIFs is necessary but not sufficient to promote IRES activity [8], demonstrating the essential function of domains 2 and 3 in IRES function. The contribution of domains 2 and 3 to IRES activity may consist in the acquisition of a proper RNA structural organization, assisted by auxiliary proteins. Along this line, while the requirement for eIFs is well established, the ITAFs involved in picornavirus IRES activity are still under study. Here we review the RNA-binding proteins (RBPs) that can form ribonucleoprotein (RNP) complexes with IRESs modulating their efficiency of translation.

2.1. Picornavirus ITAFs. Picornavirus RNAs differ on their ability to operate in the cell-free rabbit reticulocyte lysates (RRL). Early studies conducted on the PV RNA, which was inactive in RRL, evidenced that its translation efficiency was greatly enhanced upon supplementation of the lysates with HeLa cell extracts [29]. This difference was related to the requirement of factors that were missing or present in limiting amounts in RRL. Hence, addition of HeLa cells soluble extract resulted in reconstitution of PV RNA translation [30]. In due course, these observations led to the discovery of auxiliary proteins behaving as IRES trans-acting factors. Most ITAFs described so far are well characterized RBPs that contain RNA-binding motifs organized in a modular structure [31, 32], as it also occur in proteins involved in RNA processing and transport. However, modulation of IRES activity by ITAFs is not well understood, and at least in part it is a controversial issue because, depending on the IRES element, some proteins show a more stringent requirement than others do $[33,34]$.

Over the last decade, the interaction of RBPs with picornavirus IRES (Table 1) has been analyzed taking advantage of riboproteomic affinity methods. Of interest, and confirming the validity of this methodology, proteins 
TABLE 1: RNA-binding proteins interacting with viral IRES.

\begin{tabular}{|c|c|c|c|}
\hline ITAFS & Effect on IRES activity & IRES targets & $\begin{array}{l}\text { Functions in RNA } \\
\text { metabolism }\end{array}$ \\
\hline PTB & Stimulation & $\begin{array}{l}\text { FMDV, EMCV, TMEV, PV, } \\
\text { HRV, HAV, HCV }\end{array}$ & $\begin{array}{l}\text { plicing, polyadenylation, } \\
\text { RNA stability, localization }\end{array}$ \\
\hline DRBP76:NF45 & Repressor & HRV, HCV & $\begin{array}{l}\text { Transcription, RNA } \\
\text { transport, stability, viral } \\
\text { replication }\end{array}$ \\
\hline Ebp1/ PA2G4/ ITAF 45 & Stimulation & FMDV, EMCV* & Transcription regulator \\
\hline Unr & Stimulation & PV, HRV, HCV & Translation control \\
\hline HSC70 & & FMDV, HCV & Viral replication \\
\hline SRp20 & Stimulation & PV & Splicing \\
\hline \multirow[t]{2}{*}{ РCBP2 } & Stimulation & $\begin{array}{l}\text { PV, HRV, HAV, CVB3, } \\
\text { FMDV*, }^{*}\end{array}$ & $\begin{array}{l}\text { RNA stability, translation } \\
\text { control }\end{array}$ \\
\hline & & $\mathrm{EMCV}^{*}, \mathrm{HCV}$ & \\
\hline Gemin 5 & Downregulation & FMDV, HCV & $\begin{array}{l}\text { RNA-binding factor of } \\
\text { SMN complex }\end{array}$ \\
\hline hnRNP U & & FMDV & $\begin{array}{l}\text { RNA processing, stability, } \\
\text { transcription }\end{array}$ \\
\hline hnRNP K & & FMDV & $\begin{array}{l}\text { Transcription, RNA } \\
\text { stability, translation control }\end{array}$ \\
\hline DAZ1 & & FMDV & Translation control \\
\hline G3BP & & FMDV & Stress granules assembly \\
\hline Gpiap1 & & FMDV, HCV & $\begin{array}{l}\text { Transcription regulator, } \\
\text { viral replication }\end{array}$ \\
\hline Nucleolin & Stimulation & PV, HRV, FMDV, HCV & $\begin{array}{l}\text { Ribosomal RNA } \\
\text { maturation, transport }\end{array}$ \\
\hline FBP2 & Repressor & EV71 & RNA stability \\
\hline eIF2C/Ago & & FMDV & Silencing \\
\hline DHX9 & & HRV, FMDV, HCV & RNA helicase \\
\hline DDX1 & & FMDV & RNA helicase \\
\hline RACK1 & & $\mathrm{HCV}$ & Ribosomal subunits joining \\
\hline IGF2BP1 & Stimulation & $\mathrm{HCV}$ & $\begin{array}{l}\text { RNA localization, stability, } \\
\text { translation control }\end{array}$ \\
\hline $\mathrm{La}$ & Stimulation & PV, EMCV, HAV & $\begin{array}{l}\text { Transcription, translation } \\
\text { control }\end{array}$ \\
\hline NSAP1/ hnRNP Q & Stimulation & $\mathrm{HCV}$ & $\begin{array}{l}\text { RNA stability, translation } \\
\text { control, SGs component }\end{array}$ \\
\hline hnRNP L & Stimulation & $\mathrm{HCV}$ & $\begin{array}{l}\text { RNA stability, translation } \\
\text { control }\end{array}$ \\
\hline hnRNP D & Stimulation & $\mathrm{HCV}$ & $\begin{array}{l}\text { RNA stability, translation } \\
\text { control }\end{array}$ \\
\hline hnRNPA/B & & EV71, HCV & $\begin{array}{l}\text { RNA processing, } \\
\text { translation control }\end{array}$ \\
\hline GAPDH & Repressor & HAV & $\begin{array}{l}\text { RNA transport, translation } \\
\text { control }\end{array}$ \\
\hline YB-BP1 & & $\mathrm{HCV}$ & $\begin{array}{l}\text { Transcription, RNA } \\
\text { stability, translation control }\end{array}$ \\
\hline
\end{tabular}

*No effect, ${ }^{*}$ suppression. 


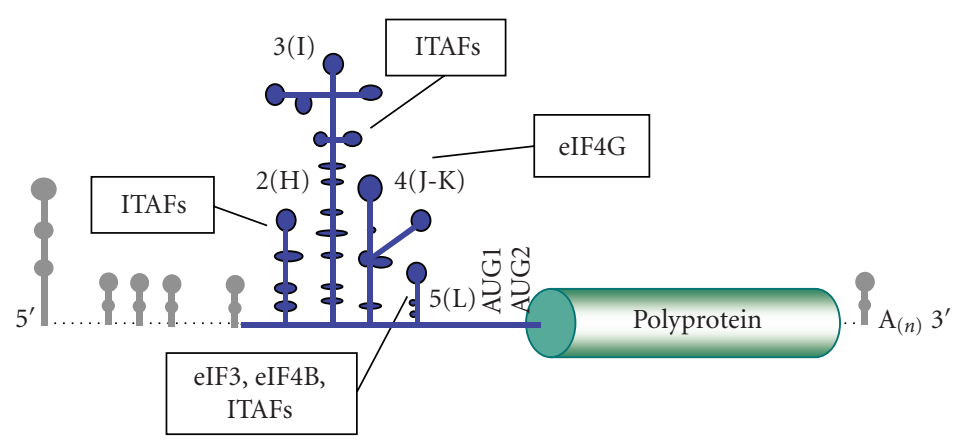

(a)

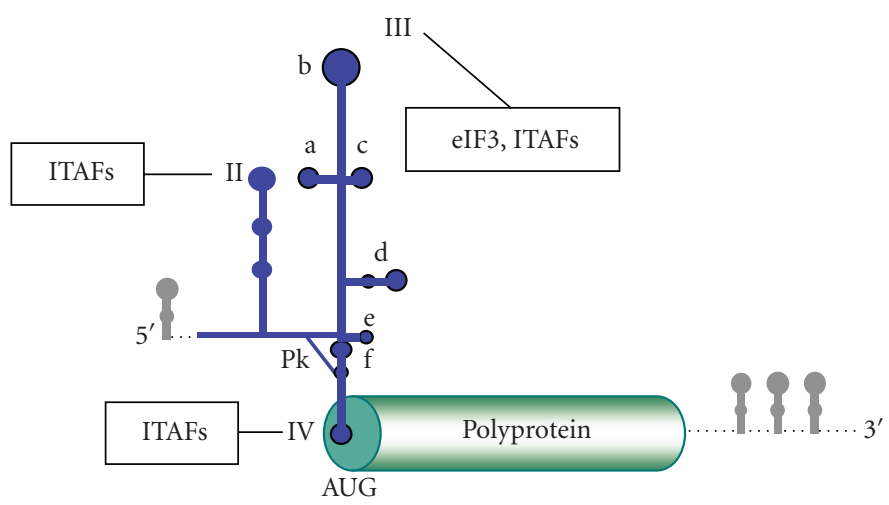

(b)

FIGURE 1: (a) Schematic representation of the picornavirus genome, using as example the foot-and-mouth disease viral RNA. (b) Schematic representation of the hepatitis $\mathrm{C}$ virus genome. The IRESs are depicted in blue, with indication of the domains referred to in the text. The position of the functional initiator AUGs, as well as the preferential binding sites of eIFs and ITAFs are indicated. Stable stem-loops located at the $5^{\prime}$ and $3^{\prime}$ end of the viral RNA are depicted in grey.

previously know to interact with IRESs by other methods were retrieved with the corresponding target RNA following affinity purification. This is the case of eIF4B and eIF3, which were specifically identified bound to FMDV or HCV IRES by mass spectrometry following RNA affinity purification [35-38].

Soon after the discovery of picornavirus IRESs, a direct interaction of the polypyrimidine tract-binding protein (PTB) with EMCV and FMDV IRESs was shown by UVcrosslinking [39-41], and later by RNA foot-printing [42] and hydroxyl radical probing [43]. PTB is a multifunctional RBP with four RNA recognition motifs (RRM) [31] that belongs to the heterogeneous nuclear ribonucleoprotein (hnRNP) family. The RRM domains of PTB recognize Urich loops on short stems and in general, U/C-rich sequences [44]. This protein was originally identified in splicingassociated RNP complexes. However, it also performs critical roles in cellular processes pertaining RNA metabolism, including polyadenylation, mRNA stability and translation initiation. Regarding its function as ITAF, PTB stimulates picornavirus and retrovirus IRESs [45], but it represses translation initiation driven by the BiP IRES [46].

As a consequence of their role as regulator of IRES activity, ITAFs can mediate cell type specificity, and hence, determine viral spread. This property was brought about by the effects of the neural form of PTB (nPTB), that determines the neurovirulence of Theiler's murine encephalitis virus (TMEV) [47], and by the double-stranded RNA-binding protein 76 (DRBP76, also termed NF90/NFAR-1), that forms a heterodimer with NF45 (nuclear factor of activated T cells). The DRBP76:NF45 heterodimer binds to the HRV2 IRES and differs in subcellular distribution in neuronal and non-neuronal malignant cells, arresting HRV translation in neuronal cells but not in glioma $[48,49]$.

Picornavirus IRESs often contain more than one polypyrimidine tract located in distant domains at each end of the IRES region [8]. Recent studies have shown that a single PTB molecule binds in a unique orientation to the EMCV IRES, with RRM1-2 contacting the $3^{\prime}$ end, and RRM3 contacting the $5^{\prime}$ end of the IRES, thereby constraining the IRES structure in a unique orientation [43]. However, studies carried out on the FMDV IRES raised the conclusion that RRM3-4 of PTB were bound in an oriented way to domain 2 and the IRES $3^{\prime}$ region, respectively [50]. Although the RRMs involved in the IRES-PTB interactions are significantly different between these two studies, both are consistent with a role of PTB in stabilizing the IRES structure, thereby acting as a chaperone.

ITAFs, as it is the case of PTB, do not act alone but in combination with various factors presumably contributing to explain the opposite effects on IRES activity [34]. Hence, RBPs interacting with different targets may result in different 
effects depending on the target and the other partners of the complex. For instance, two IRESs such as EMCV and FMDV with apparent similar secondary structure but different primary sequence, exhibit different requirements in terms of functional RNA-protein association. One example is Ebp1 protein (erbB-3-binding protein 1), also known as proliferation-associated factor PA2G4 and $\mathrm{ITAF}_{45}$, identified interacting with domain 3 of FMDV IRES in proteomic analysis [36]. Ebp1 cooperates with PTB to stimulate FMDV IRES activity in reconstitution studies [13, 51], but its depletion does not produce any effect on EMCV IRES activity [52]. This protein is expressed in proliferating cells during the $S$ phase but not during cell cycle arrest consistent with the fact that FMDV IRES is active in proliferating tissues.

Another example of a factor that mediates IRES activity is Unr (upstream of N-ras), a cold-shock RBP that interacts with PABP1 and stimulates HRV and PV translation through its interaction with two distinct IRES domains $[53,54]$. Mass spectrometry analysis identified Unr associated to the HCV IRES RNP complexes [55]. In support of the specific role of Unr in internal initiation, IRES activity of c-myc, Apaf-1, unr and PITSLRE cellular mRNAs is differentially regulated depending on the Unr-partners, hnRNP K/poly $\mathrm{r}(\mathrm{C})$-binding protein PCBP1-2, nPTB, or hnRNP C1-2, respectively [5658]. Other example of RBP identified with IRESs is the constitutive heat shock protein HSC70 [36], although the possibility of an indirect binding can not be discarded. HSC70 forms part of RNP complexes that interact with AUrich elements in the $3^{\prime}$ UTR of specific mRNAs, enhancing their stability [59].

In addition to PTB, several proteins implicated in RNA splicing can function as ITAFs, suggesting the existence of a network of interactions between different gene expression processes. An illustrative example is the splicing factor SRp20 that up-regulates PV IRES-mediated translation via its interaction with PCBP2 [60]. Another example of an ITAF involved in a different gene expression process is Gemin 5 that binds directly to FMDV and HCV IRES, acting as a downregulator of translation [61]. Not surprisingly, Gemin5 is associated with other factors in RNP complexes that perform rather different roles during gene expression control. Gemin5 is the RNA-binding factor of the survival of motor neurons (SMN) complex [62], which assembles Sm proteins on snRNAs playing a critical role in the biogenesis of key components of the mRNA splicing machinery, the small nuclear ribonucleoproteins (snRNPs) [63]. Gemin5 is a nuclear protein, but it is predominantly located in the cell cytoplasm and it also appears to be present in $\mathrm{P}$ bodies [64].

Together, the conclusions derived from the study of multifunctional proteins such as PTB, PCBP2, Gemin5 and other ITAFs, suggest a novel mechanism for the coordinated regulation of translation initiation of a subset of mRNAs bound by shuttling proteins such as hnRNPs or splicing factors. In support of this, the splicing factor SF2/ASF mediates post-splicing activities promoting translation initiation by suppressing the activity of 4E-BP [65] and modulating the internal initiation of cellular mRNAs. In fact, it has been suggested that some RBPs might exert its function in translation control by binding to the IRES of specific cellular mRNAs during splicing complex assembly before nuclear export [34]. This could be an additional layer of posttranscriptional regulation for proteins whose functions are important when cap-dependent translation is compromised.

hnRNPs are a family of proteins (named from hnRNP A1 to hnRNP $U$ ) with RNA-binding and protein-protein binding motifs $[31,66]$. They have a nuclear localization associated with nascent RNA polymerase II transcripts and shuttle with the RNA to the cytoplasm [67]. The RGG RNAbinding motif that mediates the interaction with RNA as well as with other hnRNPs was first described in hnRNP U [66], one of the factors identified by mass spectrometry interacting with the FMDV IRES [36]. Both hnRNP U and Gemin 5 form part of a complex with eIF4E, that may explain the downregulatory role of Gemin5 in cap-dependent translation [61] by virtue of eIF4E sequestration or its localization to $\mathrm{P}$ bodies [64].

Several members of the hnRNP family, hnRNP K, PCBP1 (hnRNP E1) and PCBP2 (hnRNP E2), have been identified associated with various IRESs (Table 1). These proteins have in common the KH RNA binding domain first described in hnRNP $\mathrm{K}$ and, subsequently, in PCBP1, 2,3 and 4 [68]. hnRNP $\mathrm{K}$ is the most abundant member of the family of proteins that recognize poly $(\mathrm{rC})$ regions, and regulates transcription, RNA turnover and translation $[69,70]$. Proteins hnRNP K, PCBP1 and PCBP2, together with DAZ-1, have been identified associated to domain 3 of the FMDV IRES [36]. DAZ1 is a $3^{\prime}$ UTR-binding protein that has been found bound to polysomes and stimulates translation initiation of polyadenylated mRNA [71].

PCBP2 interacts with a C-rich loop in stem-loop IV of PV, CVB3 and HRV IRESs and specifically stimulates their activity [72-75]. In contrast, the activity of EMCV and FMDV IRESs that also interact with PCBP2 was not modified by the addition of recombinant PCBP2 protein to depleted-RRL lysates [76], in agreement with the lack of effect of nucleotide substitutions in the C-rich loop of FMDV IRES [77]. PCBP2 performs a dual role in translation initiation and RNA replication of the poliovirus genome [78] through its interaction with different targets in the viral $5^{\prime}$ UTR. Furthermore, consistent with its relevance in IRES function, PV IRES competes out with the HAV IRES for PCBP2 binding [79].

The balance between translation initiation and silencing depends on the cellular response to stress. Indeed, many viruses regulate the assembly or disassembly of stress granules (SGs) modifying translation of host and virus-encoded mRNAs. Consistent with this observation, some RBPs have been localized in SGs, as PABP1 [80], or cytoplasmic processing bodies (PBs), as PCBP2 [81]. Thus, in response to stress signals including viral infection, these multifunctional proteins may perform distinct roles depending on their localization. The signaling factor Ras-GTPase-activating protein (G3BP) that was identified interacting with the FMDV IRES [36], belongs to a new family of RBPs that link tyrosin kinase-mediated signals with RNA metabolism [82]. G3BP1 localize in cytoplasmic RNA granules [83] contributing 
to its assembly [84]. These cytoplasmic aggregates contain stalled translation preinitiation complexes thought to serve as sites of mRNA storage during the cell stress response. G3BP has been found associated to the 3'UTR of HCV RNA, and its depletion induced a reduction of both HCV RNA and proteins, supporting the idea that it might be a component of $\mathrm{HCV}$ replicating complexes [85]. Interestingly, G3BP interacts with the transcriptional regulator GP1-anchored membrane protein (Gpiap1) also identified as an IRESbinding protein.

Many ITAFs are predominantly nuclear proteins that localize to the cytoplasm in picornavirus-infected cells [86]. Nucleolin is a protein involved in rDNA transcription, rRNA maturation, ribosome assembly and nucleo-cytoplasmic transport [87], and is translocated into the cytoplasm following infection of cells with poliovirus [88]. Nucleolin interacts with HRV, FMDV and PV IRES and stimulates PV IRESmediated translation in transfected cells overexpressing the full-length protein [89]. During enterovirus EV71 infection, the nuclear protein FBP2 (far upstream element (FUSE) binding protein 2) was enriched in the cytoplasm where viral replication occurs, whereas in mock-infected cells FBP2 was localized in the nucleus. FBP2 is a $\mathrm{KH}$ protein that negatively regulates EV71 IRES activity [90] presumably through its capacity to compete with PTB binding.

Together with hnRNPs, a group of proteins that are involved in gene silencing, transport, and stabilization (eIF2C, RNA helicases) have been identified in riboproteomic approaches bound to different IRESs (Table 1). The recurrent identification of a subset of factors with different RNA targets [91, 92] points to the existence of a network of RNPs with the potential for multiple levels of regulation. Moreover, the modular structure of RBPs that is at the basis of their capacity to recognize a large number of targets raises the possibility that binding to any particular RNA could facilitate different sorts of regulation depending on the other protein partners and the cellular environment.

\section{Internal Initiation of Translation in HCV RNA}

Initiation of protein synthesis in the positive-strand RNA genome of HCV is also driven by an IRES [93]. The IRES region spans 340 nucleotides and differs from picornavirus IRESs in RNA structural organization and factor requirement [94]. The HCV IRES is organized in three conserved structural domains, termed II, III and IV (Figure 1(b)) that adopt a tertiary fold whose integrity is required for efficient protein synthesis [95]. Domain II, which consists of a hairpin with basal and apical loops, is essential for HCV IRES activity. Its deletion reduces translation initiation by blocking $80 \mathrm{~S}$ formation [96]. This domain promotes eIF5-induced GTP hydrolysis during 80S ribosome assembly and eIF2/GDP release from the initiation complex [97].

Domain III consists of six stem-loops (designated IIIabcdef). The basal portion of domain III forms the core of the high-affinity interaction with the $40 \mathrm{~S}$ subunit including a small stem-loop (IIIe) and a pseudoknot (IIIf) [16]. In the absence of eIFs, the HCV IRES can establish a high-affinity interaction with ribosomal $40 \mathrm{~S}$ subunits through the binding surface between subdomains IIIabc, IIIef and IIId [98]. Despite the capacity to form binary complexes, localization of the met-tRNA $i$ on the surface of the 40 S subunit by eIF2 is essential for translation, and eIF3 significantly enhances formation of the $48 \mathrm{~S}$ initiation complex interacting with the junction of subdomains IIIabc $[5,99]$. Interaction of eIF3 subunits with HCV IRES has been analyzed by cryoelectron microscopy of the binary IRES-eIF3 complex [100] and by mass spectrometry of IRES-bound protein complexes $[36,37]$. However, under conditions of inactivation of eIF2 by phosphorylation, the HCV IRES can form a preinitiation complex in the presence of eIF3 and eIF5B [101], which is reminiscent of the bacterial-like initiation mode. The ribosomal proteins that participate in IRES-40S interaction have been identified by different approaches as well, such as cross-linking studies [102-104] and mass spectrometry [105].

Besides ribosomal proteins and eIF3 subunits, the noncanonical factors RACK1 and nucleolin were identified in native and IRES-40S ribosomal complexes [37]. RACK1 functions as the receptor for activated protein kinase C, and regulates translation initiation by recruiting protein kinase $\mathrm{C}$ to the $40 \mathrm{~S}$ subunit. It forms a stable complex with the $40 \mathrm{~S}$ subunit, exposing the WD-repeats as a platform for interactions with other proteins to the ribosome [106].

Another non-canonical host factor, the insulin-like growth factor II mRNA-binding protein 1 (IGF2BP1) has been reported to associate with both the IRES and the $3^{\prime}$ UTR of HCV, and remarkably, to coimmunoprecipitate with eIF3 and the $40 \mathrm{~S}$ subunit [38]. This result suggests that this factor may enhance HCV IRES-dependent translation by recruiting the ribosomal subunits to a pseudo-circularized RNA. In agreement with this possibility, a subset of the identified proteins, NF90/NF45, also interact with the ends of the viral RNA contributing to enhance viral RNA replication [107]. Long-range $3^{\prime}-5^{\prime}$ interactions have been reported in the HCV viral RNA [108]. Moreover, in support of the role of the $3^{\prime}-5^{\prime}$ interactions in the control of gene expression in positive-strand RNA viruses, stimulation of IRES activity by the homologous $3^{\prime}$ UTR has been shown in FMDV and HRV $[10,11]$, presumably mediated by functional bridges that bring together the RNA ends by long-range RNA-RNA interactions [109].

Despite some controversy regarding the effect of PTB, most of the identified ITAFs regulate HCV IRES activity in a positive manner $[110,111]$. La and NSAP1/hnRNP Q proteins stimulate HCV IRES-dependent translation [112]. The La autoantigen is involved in RNA polymerase III transcription. La binds to PV, EMCV and HCV IRES stimulating translation [113-115], but it suppresses HAV IRES activity [116]. NSAP1 protein has a dual function in HCV life cycle participating in RNA replication [117] and enhancing IRES-dependent translation through its binding to A-rich sequences in the core coding region [112]. 
Similar to NSAP1, hnRNP L interacts with the $3^{\prime}$ border of the HCV IRES in the core-coding sequence [118] and it is required for IRES-mediated translation [119]. This protein is necessary for efficient translation of the Cat-1 arginine/lysine transporter mRNA during amino acid starvation [120]. Other HCV-interacting protein is hnRNP D that binds to the stem-loop II and promotes translation [121]. Proteins of this family, hnRNP A/B 38, have been identified interacting with dIII of HCV IRES [36]. hnRNP A1 binds to the $5^{\prime}$ UTR of EV71 and Sindbis RNA and is required for viral RNA replication [122]. This protein also mediates internal initiation of FGF-2 and Apaf-1 mRNAs [123, 124].

In addition to direct RNA-protein interactions, proteinprotein association between RBPs, such as hnRNP $U$ or hnRNP A/B $[125,126]$ during mRNA transport can explain the identification of proteins belonging to the cytoskeleton machinery with FMDV and HCV IRES [36, 38, 55]. Proteinprotein interactions may also explain the identification of glyceraldehyde 3-phosphate dehydrogenase (GAPDH) with HAV IRES [127]. This protein competes with PTB for binding to stem-loop IIIa, suppressing the ability of the HAV 5'UTR to direct cap-independent translation [128]. GAPDH forms a macromolecular complex that binds to U-rich sequences in the $3^{\prime}$ UTR of a selective group of cellular mRNAs controlling their translation [129]. However, as already mentioned for some factors, indirect interactions may be behind the identification of very abundant RBPs, such as YB-1, in riboproteomic studies. Thus, the functional involvement of each factor as well as whether the binding is direct or mediated by another partner in the RNP complex, needs to be verified individually.

A few proteins identified by mass spectrometry with a discrete domain of the HCV IRES have been also identified in similar approaches interacting with the entire $\mathrm{HCV}$ IRES, giving additional information about the binding site of the protein. This could be the case of RNA helicase DEAH-box polypeptide 9 (DHX9) or DEAD-box polypeptide 1 (DDX1). The DDX/DHX family of proteins play important roles in nucleic acid metabolism, including premRNA processing, ribosome biogenesis, RNA turnover, RNA export, translation, and association/dissociation of large RNP complexes [130]. DHX9 recognizes a complex structure at the $5^{\prime}$-UTR of retrovirus mRNA precursors, facilitating its association to polyribosomes [131]. RNA chromatography assays showed that it is associated to HRV IRES [48]. DDX1, a dual interactor of hnRNP $\mathrm{K}$ and poly(A)-mRNA [132], has been also identified bound to the $3^{\prime} \mathrm{UTR}$ of $\mathrm{HCV}$ suggesting a role for this protein in viral RNA replication [85].

\section{Concluding Remarks}

In general, ITAFs are RNA-binding proteins that shuttle between the nucleus and the cytoplasm. Thus, a network of RNA-protein and protein-protein interactions may assist to recruit the IRES to the ribosome and possibly, to other cytoplasmic structures. RBPs are key cellular components that control the temporal, spatial and functional dynamics of RNA within the competitive cell environment. Indeed, changes in the expression of RBPs have profound implications for cellular physiology, affecting RNA processes from pre-mRNA splicing to protein translation [32]. Thereby, the composition of RNP complexes bound to the RNA in a particular situation will determine the fate of the RNA (e.g., stability, translatability, compartmentalization). In other words, binding of proteins, even those considered to be promiscuous, to a given RNA could mediate specific regulation. In agreement with this, recent mass spectrometry identification of the proteins associated with Argonaute proteins, the protein complex responsible for gene-silencing pathways guided by small RNAs, revealed a common group of helicases, hnRNPs and other RBPs which are shared with RNP complexes involved in other cellular processes such as mRNA transport, stabilization and translation [92].

The observation that proteins with the potential for multiple levels of regulation can recognize various RNA targets raises the possibility that protein-binding to specific RNAs could facilitate different sorts of regulation depending on the other partners and the cellular environment. Thus, elucidating the function of ITAFs will require a deep understanding of their RNA targets, their protein partners, and their potential modifications. Concerning the first issue, the recent advances in cross-linking immunoprecipitation and high-throughput sequencing appears to be a promising technique to help in this task. Implementation of new proteomic approaches will continue to help in the second and third tasks. Finally, regarding the modification of RBPs in infected cells, understanding the effect of proteolytic cleavage of factors such as PCBP2, PTB, PABP or G3BP [78, $133,134]$ will need to be extended to newly identified ITAFs. All together, this will help to understand the integrated action of ITAFs on mRNA targets.

The RBPs modulating picornavirus and HCV IRES activity offer promising targets to combat these infectious pathogens. Indeed, IRESs are ideal candidates to interfere with virus replication through direct IRES-targeting or through ITAF-targeting. In the first case, antiviral agents based on RNA molecules aimed to disrupt the IRES structure have been partially successful [135-138]. In the second case, knowledge of the structural organization of ITAFs provided the basis to design antiviral therapy, as shown by a synthetic peptide derived from the RRM2 of La which acts as a dominant negative inhibitor of HCV RNA translation [113]. In the coming years, elucidation of the structural determinant of peptides derived from different ITAFs, interfering with the capacity of these proteins to generate proteinprotein and RNA-protein networks, will provide the basis for developing small peptidomimetic structures as potent antiviral therapeutics.

\section{Acknowledgments}

This work was supported by Grant no.BFU2008-02159 from MICINN and by an Institutional grant from Fundación Ramón Areces. 


\section{References}

[1] T. V. Pestova, J. R. Lorsch, and C. U. T. Hellen, "The mechanism of translation initiation in eukaryotes," in Translation Control in Biology and Medicine, M. B. Mathews, N. Sonenberg, and J. W. B. Hershey, Eds., pp. 87-128, Cold Spring Harbor laboratory, Cold Spring Harbor, NY, USA, 2007.

[2] S. K. Jang, H.-G. Krausslich, M. J. H. Nicklin, G. M. Duke, A. C. Palmenberg, and E. Wimmer, "A segment of the $5^{\prime}$ nontranslated region of encephalomyocarditis virus RNA directs internal entry of ribosomes during in vitro translation," Journal of Virology, vol. 62, no. 8, pp. 2636-2643, 1988.

[3] J. Pelletier and N. Sonenberg, "Internal initiation of translation of eukaryotic mRNA directed by a sequence derived from poliovirus RNA," Nature, vol. 334, no. 6180, pp. 320-325, 1988.

[4] E. Martínez-Salas, A. Pacheco, P. Serrano, and N. Fernandez, "New insights into internal ribosome entry site elements relevant for viral gene expression," Journal of General Virology, vol. 89, no. 3, pp. 611-626, 2008.

[5] T. V. Pestova, I. N. Shatsky, S. P. Fletcher, R. J. Jackson, and C. U. T. Hellen, "A prokaryotic-like mode of cytoplasmic eukaryotic ribosome binding to the initiation codon during internal translation initation of hepatitis C and classical swine fever virus RNAs," Genes and Development, vol. 12, no. 1, pp. 67-83, 1998.

[6] C. M. T. Spahn, J. S. Kieft, R. A. Grassucci, et al., "Hepatitis $\mathrm{C}$ virus IRES RNA-induced changes in the conformation of the 40 S ribosomal subunit," Science, vol. 291, no. 5510, pp. 1959-1962, 2001.

[7] S. D. Baird, M. Turcotte, R. G. Korneluk, and M. Holcik, "Searching for IRES," RNA, vol. 12, no. 10, pp. 1755-1785, 2006.

[8] O. Fernández-Miragall, S. López de Quinto, and E. MartínezSalas, "Relevance of RNA structure for the activity of picornavirus IRES elements," Virus Research, vol. 139, no. 2, pp. 172-182, 2009.

[9] M. Sáiz, S. Gómez, E. Martínez-Salas, and F. Sobrino, "Deletion or substitution of the aphthovirus 3' NCR abrogates infectivity and virus replication," Journal of General Virology, vol. 82, no. 1, pp. 93-101, 2001.

[10] S. López de Quinto, M. Sáiz, D. de La Morena, F. Sobrino, and E. Martínez-Salas, "IRES-driven translation is stimulated separately by the FMDV 3 '-NCR and poly(A) sequences," Nucleic Acids Research, vol. 30, no. 20, pp. 4398-4405, 2002.

[11] E. Dobrikova, P. Florez, S. Bradrick, and M. Gromeier, "Activity of a type 1 picornavirus internal ribosomal entry site is determined by sequences within the 3 ' nontranslated region," Proceedings of the National Academy of Sciences of the United States of America, vol. 100, no. 25, pp. 15125-15130, 2003.

[12] S. López de Quinto and E. Martínez-Salas, "Involvement of the aphthovirus RNA region located between the two functional AUGs in start codon selection," Virology, vol. 255, no. 2, pp. 324-336, 1999.

[13] D. E. Andreev, O. Fernández-Miragall, J. Ramajo, et al., "Differential factor requirement to assemble translation initiation complexes at the alternative start codons of foot-and-mouth disease virus RNA," RNA, vol. 13, no. 8, pp. 1366-1374, 2007.

[14] E. Martínez-Salas, "The impact of RNA structure on picornavirus IRES activity," Trends in Microbiology, vol. 16, no. 5, pp. 230-237, 2008.

[15] G. J. Belsham, "Divergent picornavirus IRES elements," Virus Research, vol. 139, no. 2, pp. 183-192, 2009.
[16] P. J. Lukavsky, "Structure and function of HCV IRES domains," Virus Research, vol. 139, no. 2, pp. 166-171, 2009.

[17] J. S. Kieft, "Comparing the three-dimensional structures of Dicistroviridae IGR IRES RNAs with other viral RNA structures," Virus Research, vol. 139, no. 2, pp. 148-156, 2009.

[18] S. López de Quinto and E. Martínez-Salas, "Conserved structural motifs located in distal loops of aphthovirus internal ribosome entry site domain 3 are required for internal initiation of translation," Journal of Virology, vol. 71, no. 5, pp. 4171-4175, 1997.

[19] M. E. M. Robertson, R. A. Seamons, and G. J. Belsham, "A selection system for functional internal ribosome entry site (IRES) elements: analysis of the requirement for a conserved GNRA tetraloop in the encephalomyocarditis virus IRES," RNA, vol. 5, no. 9, pp. 1167-1179, 1999.

[20] O. Fernández-Miragall and E. Martínez-Salas, "Structural organization of a viral IRES depends on the integrity of the GNRA motif," RNA, vol. 9, no. 11, pp. 1333-1344, 2003.

[21] O. Fernández-Miragall, R. Ramos, J. Ramajo, and E. Martínez-Salas, "Evidence of reciprocal tertiary interactions between conserved motifs involved in organizing RNA structure essential for internal initiation of translation," RNA, vol. 12, no. 2, pp. 223-234, 2006.

[22] P. Serrano, J. Gomez, and E. Martínez-Salas, "Characterization of a cyanobacterial RNase P ribozyme recognition motif in the IRES of foot-and-mouth disease virus reveals a unique structural element," RNA, vol. 13, no. 6, pp. 849-859, 2007.

[23] P. Serrano, J. Ramajo, and E. Martínez-Salas, "Rescue of internal initiation of translation by RNA complementation provides evidence for a distribution of functions between individual IRES domains," Virology, vol. 388, no. 1, pp. 221-229, 2009.

[24] V. G. Kolupaeva, T. V. Pestova, C. U. T. Hellen, and I. N. Shatsky, "Translation eukaryotic initiation factor $4 \mathrm{G}$ recognizes a specific structural element within the internal ribosome entry site of encephalomyocarditis virus RNA," Journal of Biological Chemistry, vol. 273, no. 29, pp. 1859918604, 1998.

[25] S. de Breyne, Y. Yu, A. Unbehaun, T. V. Pestova, and C. U. T. Hellen, "Direct functional interaction of initiation factor eIF4G with type 1 internal ribosomal entry sites," Proceedings of the National Academy of Sciences of the United States of America, vol. 106, no. 23, pp. 9197-9202, 2009.

[26] S. López de Quinto, E. Lafuente, and E. Martínez-Salas, "IRES interaction with translation initiation factors: functional characterization of novel RNA contacts with eIF3, eIF4B, and eIF4GII," RNA, vol. 7, no. 9, pp. 1213-1226, 2001.

[27] S. López de Quinto and E. Martínez-Salas, "Interaction of the elF4G initiation factor with the aphthovirus IRES is essential for internal translation initiation in vivo," RNA, vol. 6, no. 10, pp. 1380-1392, 2000.

[28] A. T. Clark, M. E. M. Robertson, G. L. Conn, and G. J. Belsham, "Conserved nucleotides within the J domain of the encephalomyocarditis virus internal ribosome entry site are required for activity and for interaction with eIF4G," Journal of Virology, vol. 77, no. 23, pp. 12441-12449, 2003.

[29] A. J. Dorner, B. L. Semler, R. J. Jackson, R. Hanecak, E. Duprey, and E. Wimmer, "In vitro translation of poliovirus RNA: utilization of internal initiation sites in reticulocyte lysate," Journal of Virology, vol. 50, no. 2, pp. 507-514, 1984.

[30] J. R. Gebhard and E. Ehrenfeld, "Specific interactions of HeLa cell proteins with proposed translation domains of the poliovirus 5 ' noncoding region," Journal of Virology, vol. 66, no. 5, pp. 3101-3109, 1992. 
[31] B. M. Lunde, C. Moore, and G. Varani, "RNA-binding proteins: modular design for efficient function," Nature Reviews Molecular Cell Biology, vol. 8, no. 6, pp. 479-490, 2007.

[32] K. E. Lukong, K. Chang, E. W. Khandjian, and S. Richard, "RNA-binding proteins in human genetic disease," Trends in Genetics, vol. 24, no. 8, pp. 416-425, 2008.

[33] E. Martínez-Salas, O. Fernández-Miragall, S. Reigadas, A. Pacheco, and P. Serrano, "Internal ribosome entry site elements in eukaryotic genomes," Current Genomics, vol. 5, no. 3, pp. 259-277, 2004.

[34] K. Sawicka, M. Bushell, K. A. Spriggs, and A. E. Willis, "Polypyrimidine-tract-binding protein: a multifunctional RNA-binding protein," Biochemical Society Transactions, vol. 36, no. 4, pp. 641-647, 2008.

[35] S. Reigadas, A. Pacheco, J. Ramajo, S. López de Quinto, and E. Martínez-Salas, "Specific interference between two unrelated internal ribosome entry site elements impairs translation efficiency," FEBS Letters, vol. 579, no. 30, pp. 6803-6808, 2005.

[36] A. Pacheco, S. Reigadas, and E. Martínez-Salas, "Riboproteomic analysis of polypeptides interacting with the internal ribosome-entry site element of foot-and-mouth disease viral RNA," Proteomics, vol. 8, no. 22, pp. 4782-4790, 2008.

[37] Y. Yu, H. Ji, J. A. Doudna, and J. A. Leary, "Mass spectrometric analysis of the human $40 \mathrm{~S}$ ribosomal subunit: native and HCV IRES-bound complexes," Protein Science, vol. 14, no. 6, pp. 1438-1446, 2005.

[38] S. Weinlich, S. Hüttelmaier, A. Schierhorn, S.-E. Behrens, A. Ostareck-Lederer, and D. H. Ostareck, "IGF2BP1 enhances HCV IRES-mediated translation initiation via the $3^{\prime}$ UTR," RNA, vol. 15, no. 8, pp. 1528-1542, 2009.

[39] N. Luz and E. Beck, "A cellular $57 \mathrm{kDa}$ protein binds to two regions of the internal translation initiation site of foot-and-mouth disease virus," FEBS Letters, vol. 269, no. 2, pp. 311-314, 1990.

[40] S. K. Jang and E. Wimmer, "Cap-independent translation of encephalomyocarditis virus RNA: structural elements of the internal ribosomal entry site and involvement of a cellular 57-kD RNA-binding protein," Genes and Development, vol. 4, no. 9, pp. 1560-1572, 1990.

[41] A. Borman, M. T. Howell, J. G. Patton, and R. J. Jackson, "The involvement of a spliceosome component in internal initiation of human rhinovirus RNA translation," Journal of General Virology, vol. 74, no. 9, pp. 1775-1788, 1993.

[42] V. G. Kolupaeva, C. U. T. Hellen, and I. N. Shatsky, "Structural analysis of the interaction of the pyrimidine tract-binding protein with the internal ribosomal entry site of encephalomyocarditis virus and foot-and-mouth disease virus RNAs," RNA, vol. 2, no. 12, pp. 1199-1212, 1996.

[43] P. Kafasla, N. Morgner, T. A. A. Pöyry, S. Curry, C. V. Robinson, and R. J. Jackson, "Polypyrimidine tract binding protein stabilizes the encephalomyocarditis virus IRES structure via binding multiple sites in a unique orientation," Molecular Cell, vol. 34, no. 5, pp. 556-568, 2009.

[44] M. R. Conte, T. Grüne, J. Ghuman, et al., "Structure of tandem RNA recognition motifs from polypyrimidine tract binding protein reveals novel features of the RRM fold," EMBO Journal, vol. 19, no. 12, pp. 3132-3141, 2000.

[45] P. M. Florez, O. M. Sessions, E. J. Wagner, M. Gromeier, and M. A. Garcia-Blanco, "The polypyrimidine tract binding protein is required for efficient picornavirus gene expression and propagation," Journal of Virology, vol. 79, no. 10, pp. 6172-6179, 2005.
[46] Y. K. Kim, B. Hahm, and S. K. Jang, "Polypyrimidine tractbinding protein inhibits translation of bip mRNA," Journal of Molecular Biology, vol. 304, no. 2, pp. 119-133, 2000.

[47] E. V. Pilipenko, E. G. Viktorova, S. T. Guest, V. I. Agol, and R. P. Roos, "Cell-specific proteins regulate viral RNA translation and virus-induced disease," EMBO Journal, vol. 20, no. 23, pp. 6899-6908, 2001.

[48] M. K. Merrill, E. Y. Dobrikova, and M. Gromeier, "Cell-typespecific repression of internal ribosome entry site activity by double-stranded RNA-binding protein 76," Journal of Virology, vol. 80, no. 7, pp. 3147-3156, 2006.

[49] M. K. Merrill and M. Gromeier, "The double-stranded RNA binding protein 76:NF45 heterodimer inhibits translation initiation at the rhinovirus type 2 internal ribosome entry site," Journal of Virology, vol. 80, no. 14, pp. 6936-6942, 2006.

[50] Y. Song, E. Tzima, K. Ochs, et al., "Evidence for an RNA chaperone function of polypyrimidine tract-binding protein in picornavirus translation," $R N A$, vol. 11, no. 12, pp. 1809-1824, 2005.

[51] E. V. Pilipenko, T. V. Pestova, V. G. Kolupaeva, et al., "A cell cycle-dependent protein serves as a template-specific translation initiation factor," Genes and Development, vol. 14, no. 16, pp. 2028-2045, 2000.

[52] T. P. Monie, A. J. Perrin, J. R. Birtley, et al., "Structural insights into the transcriptional and translational roles of Ebp1," EMBO Journal, vol. 26, no. 17, pp. 3936-3944, 2007.

[53] O. Boussadia, M. Niepmann, L. Créancier, A.-C. Prats, F. Dautry, and H. Jacquemin-Sablon, "Unr is required in vivo for efficient initiation of translation from the internal ribosome entry sites of both rhinovirus and poliovirus," Journal of Virology, vol. 77, no. 6, pp. 3353-3359, 2003.

[54] E. C. Anderson, S. L. Hunt, and R. J. Jackson, "Internal initiation of translation from the human rhinovirus-2 internal ribosome entry site requires the binding of Unr to two distinct sites on the $5^{\prime}$ untranslated region," Journal of General Virology, vol. 88, no. 11, pp. 3043-3052, 2007.

[55] H. Lu, W. Li, W. S. Noble, D. Payan, and D. C. Anderson, "Riboproteomics of the hepatitis $\mathrm{C}$ virus internal ribosomal entry site," Journal of Proteome Research, vol. 3, no. 5, pp. 949-957, 2004.

[56] J. R. Evans, S. A. Mitchell, K. A. Spriggs, et al., "Members of the poly $(\mathrm{rC})$ binding protein family stimulate the activity of the c-myc internal ribosome entry segment in vitro and in vivo," Oncogene, vol. 22, no. 39, pp. 8012-8020, 2003.

[57] S. A. Mitchell, K. A. Spriggs, M. J. Coldwell, R. J. Jackson, and A. E. Willis, "The Apaf-1 internal ribosome entry segment attains the correct structural conformation for function via interactions with PTB and Unr," Molecular Cell, vol. 11, no. 3, pp. 757-771, 2003.

[58] B. Schepens, S. A. Tinton, Y. Bruynooghe, et al., "A role for hnRNP C1/C2 and Unr in internal initiation of translation during mitosis," EMBO Journal, vol. 26, no. 1, pp. 158-169, 2007.

[59] H. Matsui, H. Asou, and T. Inaba, "Cytokines direct the regulation of Bim mRNA stability by heat-shock cognate protein 70," Molecular Cell, vol. 25, no. 1, pp. 99-112, 2007.

[60] K. M. Bedard, S. Daijogo, and B. L. Semler, "A nucleocytoplasmic SR protein functions in viral IRES-mediated translation initiation," EMBO Journal, vol. 26, no. 2, pp. 459-467, 2007.

[61] A. Pacheco, S. López de Quinto, J. Ramajo, N. Fernández, and E. Martínez-Salas, "A novel role for Gemin5 in mRNA translation," Nucleic Acids Research, vol. 37, no. 2, pp. 582-590, 2009. 
[62] D. J. Battle, C.-K. Lau, L. Wan, H. Deng, F. Lotti, and G. Dreyfuss, "The Gemin5 protein of the SMN complex identifies snRNAs," Molecular Cell, vol. 23, no. 2, pp. 273-279, 2006.

[63] C. L. Will and R. Lührmann, "Spliceosomal UsnRNP biogenesis, structure and function," Current Opinion in Cell Biology, vol. 13, no. 3, pp. 290-301, 2001.

[64] I. Fierro-Monti, S. Mohammed, R. Matthiesen, et al., "Quantitative proteomics identifies Gemin5, a scaffolding protein involved in ribonucleoprotein assembly, as a novel partner for eukaryotic initiation factor 4E," Journal of Proteome Research, vol. 5, no. 6, pp. 1367-1378, 2006.

[65] G. Michlewski, J. R. Sanford, and J. F. Cáceres, "The splicing factor SF2/ASF regulates translation initiation by enhancing phosphorylation of 4E-BP1," Molecular Cell, vol. 30, no. 2, pp. 179-189, 2008.

[66] M. Kiledjian and G. Dreyfuss, "Primary structure and binding activity of the hnRNP $U$ protein: binding RNA through RGG box," EMBO Journal, vol. 11, no. 7, pp. 2655-2664, 1992.

[67] J. H. Kim, B. Hahm, Y. K. Kim, M. Choi, and S. K. Jang, "Protein-protein interaction among hnRNPs shuttling between nucleus and cytoplasm," Journal of Molecular Biology, vol. 298, no. 3, pp. 395-405, 2000.

[68] A. V. Makeyev and S. A. Liebhaber, "The poly(C)-binding proteins: a multiplicity of functions and a search for mechanisms," RNA, vol. 8, no. 3, pp. 265-278, 2002.

[69] M. Lynch, L. Chen, M. J. Ravitz, et al., "hnRNP K binds a core polypyrimidine element in the eukaryotic translation initiation factor $4 \mathrm{E}$ (eIF4E) promoter, and its regulation of eIF4E contributes to neoplastic transformation," Molecular and Cellular Biology, vol. 25, no. 15, pp. 6436-6453, 2005.

[70] P.-T. Lee, P.-C. Liao, W.-C. Chang, and J. T. Tseng, "Epidermal growth factor increases the interaction between nucleolin and heterogeneous nuclear ribonucleoprotein $\mathrm{K} /$ poly $(\mathrm{C})$ binding protein 1 complex to regulate the gastrin mRNA turnover," Molecular Biology of the Cell, vol. 18, no. 12, pp. 5004-5013, 2007.

[71] B. Collier, B. Gorgoni, C. Loveridge, H. J. Cooke, and N. K. Gray, "The DAZL family proteins are PABP-binding proteins that regulate translation in germ cells," EMBO Journal, vol. 24, no. 14, pp. 2656-2666, 2005.

[72] L. B. Blyn, J. S. Towner, B. L. Semler, and E. Ehrenfeld, "Requirement of poly $(\mathrm{rC})$ binding protein 2 for translation of poliovirus RNA," Journal of Virology, vol. 71, no. 8, pp. 6243-6246, 1997.

[73] A. V. Gamarnik, N. Böddeker, and R. Andino, "Translation and replication of human rhinovirus type 14 and mengovirus in Xenopus oocytes," Journal of Virology, vol. 74, no. 24, pp. 11983-11987, 2000.

[74] K. Choi, J. H. Kim, X. Li, et al., "Identification of cellular proteins enhancing activities of internal ribosomal entry sites by competition with oligodeoxynucleotides," Nucleic Acids Research, vol. 32, no. 4, pp. 1308-1317, 2004.

[75] P. Sean, J. H. C. Nguyen, and B. L. Semler, "Altered interactions between stem-loop IV within the $5^{\prime}$ noncoding region of coxsackievirus RNA and poly $(\mathrm{rC})$ binding protein 2: effects on IRES-mediated translation and viral infectivity," Virology, vol. 389, no. 1-2, pp. 45-58, 2009.

[76] B. L. Walter, J. H. C. Nguyen, E. Ehrenfeld, and B. L. Semler, "Differential utilization of poly $(\mathrm{rC})$ binding protein 2 in translation directed by picornavirus IRES elements," RNA, vol. 5, no. 12, pp. 1570-1585, 1999.
[77] E. Martínez-Salas, S. López de Quinto, R. Ramos, and O. Fernández-Miragall, "IRES elements: features of the RNA structure contributing to their activity," Biochimie, vol. 84, no. 8, pp. 755-763, 2002.

[78] R. Perera, S. Daijogo, B. L. Walter, J. H. C. Nguyen, and B. L. Semler, "Cellular protein modification by poliovirus: the two faces of poly(rC)-binding protein," Journal of Virology, vol. 81, no. 17, pp. 8919-8932, 2007.

[79] J. Graff, J. Cha, L. B. Blyn, and E. Ehrenfeld, "Interaction of poly $(\mathrm{rC})$ binding protein 2 with the $5^{\prime}$ noncoding region of hepatitis A virus RNA and its effects on translation," Journal of Virology, vol. 72, no. 12, pp. 9668-9675, 1998.

[80] C. Candé, N. Vahsen, D. Métivier, et al., "Regulation of cytoplasmic stress granules by apoptosis-inducing factor," Journal of Cell Science, vol. 117, no. 19, pp. 4461-4468, 2004.

[81] K. Fujimura, J. Katahira, F. Kano, Y. Yoneda, and M. Murata, "Selective localization of PCBP2 to cytoplasmic processing bodies," Biochimica et Biophysica Acta, vol. 1793, no. 5, pp. 878-887, 2009.

[82] F. Parker, F. Maurier, I. Delumeau, et al., "A Ras-GTPaseactivating protein SH3-domain-binding protein," Molecular and Cellular Biology, vol. 16, no. 6, pp. 2561-2569, 1996.

[83] S. Solomon, Y. Xu, B. Wang, et al., "Distinct structural features of caprin-1 mediate its interaction with G3BP-1 and its induction of phosphorylation of eukaryotic translation initiation factor $2 \alpha$, entry to cytoplasmic stress granules, and selective interaction with a subset of mRNAs," Molecular and Cellular Biology, vol. 27, no. 6, pp. 2324-2342, 2007.

[84] H. Tourrière, K. Chebli, L. Zekri, et al., "The RasGAPassociated endoribonuclease G3BP assembles stress granules," Journal of Cell Biology, vol. 160, no. 6, pp. 823-831, 2003.

[85] P. Tingting, F. Caiyun, Y. Zhigang, Y. Pengyuan, and Y. Zhenghong, "Subproteomic analysis of the cellular proteins associated with the $3^{\prime}$ untranslated region of the hepatitis $\mathrm{C}$ virus genome in human liver cells," Biochemical and Biophysical Research Communications, vol. 347, no. 3, pp. 683-691, 2006.

[86] K. E. Gustin and P. Sarnow, "Effects of poliovirus infection on nucleo-cytoplasmic trafficking and nuclear pore complex composition," EMBO Journal, vol. 20, no. 1-2, pp. 240-249, 2001.

[87] H. Ginisty, H. Sicard, B. Roger, and P. Bouvet, "Structure and functions of nucleolin," Journal of Cell Science, vol. 112, no. 6, pp. 761-772, 1999.

[88] S. Waggoner and P. Sarnow, "Viral ribonucleoprotein complex formation and nucleolar-cytoplasmic relocalization of nucleolin in poliovirus-infected cells," Journal of Virology, vol. 72, no. 8, pp. 6699-6709, 1998.

[89] R. E. Izumi, B. Valdez, R. Banerjee, M. Srivastava, and A. Dasgupta, "Nucleolin stimulates viral internal ribosome entry site-mediated translation," Virus Research, vol. 76, no. 1, pp. 17-29, 2001.

[90] J.-Y. Lin, M.-L. Li, and S.-R. Shih, "Far upstream element binding protein 2 interacts with enterovirus 71 internal ribosomal entry site and negatively regulates viral translation," Nucleic Acids Research, vol. 37, no. 1, pp. 47-59, 2009.

[91] J. Höck, L. Weinmann, C. Ender, et al., "Proteomic and functional analysis of Argonaute-containing mRNA-protein complexes in human cells," EMBO Reports, vol. 8, no. 11, pp. 1052-1060, 2007. 
[92] M. Landthaler, D. Gaidatzis, A. Rothballer, et al., "Molecular characterization of human Argonaute-containing ribonucleoprotein complexes and their bound target mRNAs," RNA, vol. 14, no. 12, pp. 2580-2596, 2008.

[93] K. Tsukiyama-Kohara, N. Iizuka, M. Kohara, and A. Nomoto, "Internal ribosome entry site within hepatitis C virus RNA," Journal of Virology, vol. 66, no. 3, pp. 1476-1483, 1992.

[94] C. S. Fraser and J. A. Doudna, "Structural and mechanistic insights into hepatitis C viral translation initiation," Nature Reviews Microbiology, vol. 5, no. 1, pp. 29-38, 2007.

[95] C. Wang, S.-Y. Le, N. Ali, and A. Siddiqui, "An RNA pseudoknot is an essential structural element of the internal ribosome entry site located within the hepatitis $\mathrm{C}$ virus $5^{\prime}$ noncoding region," RNA, vol. 1, no. 5, pp. 526-537, 1995.

[96] G. A. Otto and J. D. Puglisi, "The pathway of HCV IRESmediated translation initiation," Cell, vol. 119, no. 3, pp. 369-380, 2004.

[97] N. Locker, L. E. Easton, and P. J. Lukavsky, "HCV and CSFV IRES domain II mediate eIF2 release during $80 \mathrm{~S}$ ribosome assembly," EMBO Journal, vol. 26, no. 3, pp. 795-805, 2007.

[98] J. S. Kieft, K. Zhou, R. Jubin, and J. A. Doudna, "Mechanism of ribosome recruitment by hepatitis C IRES RNA," RNA, vol. 7, no. 2, pp. 194-206, 2001.

[99] E. Buratti, S. Tisminetzky, M. Zotti, and F. E. Baralle, "Functional analysis of the interaction between HCV 5' UTR and putative subunits of eukaryotic translation initiation factor elF3," Nucleic Acids Research, vol. 26, no. 13, pp. 3179-3187, 1998.

[100] B. Siridechadilok, C. S. Fraser, R. J. Hall, J. A. Doudna, and E. Nogales, "Molecular biology: structural roles for human translation factor elF3 in initiation of protein synthesis," Science, vol. 310, no. 5753, pp. 1513-1515, 2005.

[101] I. M. Terenin, S. E. Dmitriev, D. E. Andreev, and I. N. Shatsky, "Eukaryotic translation initiation machinery can operate in a bacterial-like mode without eIF2," Nature Structural and Molecular Biology, vol. 15, no. 8, pp. 836-841, 2008.

[102] S. Fukushi, M. Okada, J. Stahl, T. Kageyama, F. B. Hoshino, and K. Katayama, "Ribosomal protein S5 interacts with the internal ribosomal entry site of hepatitis C virus," Journal of Biological Chemistry, vol. 276, no. 24, pp. 20824-20826, 2001.

[103] E. Laletina, D. Graifer, A. Malygin, A. Ivanov, I. Shatsky, and G. Karpova, "Proteins surrounding hairpin IIIe of the hepatitis $\mathrm{C}$ virus internal ribosome entry site on the human 40S ribosomal subunit," Nucleic Acids Research, vol. 34, no. 7, pp. 2027-2036, 2006.

[104] G. A. Otto, P. J. Lukavsky, A. M. Lancaster, P. Sarnow, and J. D. Puglisi, "Ribosomal proteins mediate the hepatitis $\mathrm{C}$ virus IRES-HeLa 40S interaction,” RNA, vol. 8, no. 7, pp. 913-923, 2002.

[105] H. Ji, C. S. Fraser, Y. Yu, J. Leary, and J. A. Doudna, "Coordinated assembly of human translation initiation complexes by the hepatitis C virus internal ribosome entry site RNA," Proceedings of the National Academy of Sciences of the United States of America, vol. 101, no. 49, pp. 16990-16995, 2004.

[106] J. Sengupta, J. Nilsson, R. Gursky, C. M. T. Spahn, P. Nissen, and J. Frank, "Identification of the versatile scaffold protein RACK1 on the eukaryotic ribosome by cryo-EM," Nature Structural and Molecular Biology, vol. 11, no. 10, pp. 957-962, 2004.

[107] O. Isken, M. Baroth, C. W. Grassmann, et al., "Nuclear factors are involved in hepatitis C virus RNA replication," $R N A$, vol. 13, no. 10, pp. 1675-1692, 2007.
[108] C. Romero-López and A. Berzal-Herranz, "A long-range RNA-RNA interaction between the $5^{\prime}$ and $3^{\prime}$ ends of the HCV genome," RNA, vol. 15, no. 9, pp. 1740-1752, 2009.

[109] P. Serrano, M. R. Pulido, M. Saiz, and E. Martínez-Salas, "The 3 ' end of the foot-and-mouth disease virus genome establishes two distinct long-range RNA-RNA interactions with the $5^{\prime}$ and region," Journal of General Virology, vol. 87, no. 10, pp. 3013-3022, 2006.

[110] R. Gosert, K. H. Chang, R. Rijnbrand, M. Yi, D. V. Sangar, and S. M. Lemon, "Transient expression of cellular polypyrimidine-tract binding protein stimulates capindependent translation directed by both picornaviral and flaviviral internal ribosome entry sites in vivo," Molecular and Cellular Biology, vol. 20, no. 5, pp. 1583-1595, 2000.

[111] Y. Song, P. Friebe, E. Tzima, C. Jünemann, R. Bartenschlager, and M. Niepmann, "The hepatitis C virus RNA 3'untranslated region strongly enhances translation directed by the internal ribosome entry site," Journal of Virology, vol. 80, no. 23, pp. 11579-11588, 2006.

[112] J. H. Kim, K. Y. Paek, S. H. Ha, et al., "A cellular RNA-binding protein enhances internal ribosomal entry site-dependent translation through an interaction downstream of the hepatitis C virus polyprotein initiation codon," Molecular and Cellular Biology, vol. 24, no. 18, pp. 7878-7890, 2004.

[113] T. Mondal, U. Ray, A. K. Manna, R. Gupta, S. Roy, and S. Das, "Structural determinant of human La protein critical for internal initiation of translation of hepatitis C virus RNA," Journal of Virology, vol. 82, no. 23, pp. 11927-11938, 2008.

[114] K. Meerovitch, Y. V. Svitkin, H. S. Lee, et al., "La autoantigen enhances and corrects aberrant translation of poliovirus RNA in reticulocyte lysate," Journal of Virology, vol. 67, no. 7, pp. 3798-3807, 1993.

[115] Y. K. Kim and S. K. Jang, "La protein is required for efficient translation driven by encephalomyocarditis virus internal ribosomal entry site," Journal of General Virology, vol. 80, no. 12, pp. 3159-3166, 1999.

[116] S. Cordes, Y. Kusov, T. Heise, and V. Gauss-Müller, "La autoantigen suppresses IRES-dependent translation of the hepatitis A virus," Biochemical and Biophysical Research Communications, vol. 368, no. 4, pp. 1014-1019, 2008.

[117] H. M. Liu, H. Aizaki, K. S. Choi, K. Machida, J. J.-H. Ou, and M. M. C. Lai, "SYNCRIP (synaptotagmin-binding, cytoplasmic RNA-interacting protein) is a host factor involved in hepatitis C virus RNA replication," Virology, vol. 386, no. 2, pp. 249-256, 2009.

[118] B. Hahm, Y. K. Kim, J. H. Kim, T. Y. Kim, and S. K. Jang, "Heterogeneous nuclear ribonucleoprotein L interacts with the $3^{\prime}$ border of the internal ribosomal entry site of hepatitis C virus," Journal of Virology, vol. 72, no. 11, pp. 8782-8788, 1998.

[119] B. Hwang, J. H. Lim, B. Hahm, S. K. Jang, and S.-W. Lee, "hnRNP $\mathrm{L}$ is required for the translation mediated by HCV IRES," Biochemical and Biophysical Research Communications, vol. 378, no. 3, pp. 584-588, 2009.

[120] M. Majumder, I. Yaman, F. Gaccioli, et al., "The hnRNAbinding proteins hnRNP L and PTB are required for efficient translation of the Cat-1 arginine/lysine transporter mRNA during amino acid starvation," Molecular and Cellular Biology, vol. 29, no. 10, pp. 2899-2912, 2009.

[121] K. Y. Paek, C. S. Kim, S. M. Park, J. H. Kim, and S. K. Jang, "RNA-binding protein hnRNP D modulates internal ribosome entry site-dependent translation of hepatitis C Virus RNA," Journal of Virology, vol. 82, no. 24, pp. 12082-12093, 2008 
[122] J.-Y. Lin, S.-R. Shih, M. Pan, et al., "hnRNP A1 interacts with the $3^{\prime}$ untranslated regions of enterovirus 71 and Sindbis virus RNA and is required for viral replication," Journal of Virology, vol. 83, no. 12, pp. 6106-6114, 2009.

[123] S. Bonnal, F. Pileur, C. Orsini, et al., "Heterogeneous nuclear ribonucleoprotein $\mathrm{A} 1$ is a novel internal ribosome entry site trans-acting factor that modulates alternative initiation of translation of the fibroblast growth factor 2 mRNA," Journal of Biological Chemistry, vol. 280, no. 6, pp. 4144-4153, 2005.

[124] A. Cammas, F. Pileur, S. Bonnal, et al., "Cytoplasmic relocalization of heterogeneous nuclear ribonucleoprotein A1 controls translation initiation of specific mRNAs," Molecular Biology of the Cell, vol. 18, no. 12, pp. 5048-5059, 2007.

[125] A. Kukalev, Y. Nord, C. Palmberg, T. Bergman, and P. Percipalle, "Actin and hnRNP U cooperate for productive transcription by RNA polymerase II," Nature Structural and Molecular Biology, vol. 12, no. 3, pp. 238-244, 2005.

[126] P. Percipalle, A. Jonsson, D. Nashchekin, et al., "Nuclear actin is associated with a specific subset of hnRNP A/Btype proteins," Nucleic Acids Research, vol. 30, no. 8, pp. 1725-1734, 2002.

[127] D. E. Schultz, C. C. Hardin, and S. M. Lemon, "Specific interaction of glyceraldehyde 3-phosphate dehydrogenase with the $5^{\prime}$-nontranslated RNA of hepatitis a virus," Journal of Biological Chemistry, vol. 271, no. 24, pp. 14134-14142, 1996.

[128] M. Yi, D. E. Schultz, and S. M. Lemon, "Functional significance of the interaction of hepatitis A virus RNA with glyceraldehyde 3-phosphate dehydrogenase (GAPDH): opposing effects of GAPDH and polypyrimidine tract binding protein on internal ribosome entry site function," Journal of Virology, vol. 74, no. 14, pp. 6459-6468, 2000.

[129] R. Mukhopadhyay, J. Jia, A. Arif, P. S. Ray, and P. L. Fox, "The GAIT system: a gatekeeper of inflammatory gene expression," Trends in Biochemical Sciences, vol. 34, no. 7, pp. 324-331, 2009.

[130] F. V. Fuller-Pace, "DExD/H box RNA helicases: multifunctional proteins with important roles in transcriptional regulation," Nucleic Acids Research, vol. 34, no. 15, pp. 4206-4215, 2006.

[131] T. R. Hartman, S. Qian, C. Bolinger, S. Fernandez, D. R. Schoenberg, and K. Boris-Lawrie, "RNA helicase A is necessary for translation of selected messenger RNAs," Nature Structural and Molecular Biology, vol. 13, no. 6, pp. 509-516, 2006.

[132] H.-C. Chen, W.-C. Lin, Y.-G. Tsay, S.-C. Lee, and C.-J. Chang, "An RNA helicase, DDX1, interacting with poly(A) RNA and heterogeneous nuclear ribonucleoprotein K," Journal of Biological Chemistry, vol. 277, no. 43, pp. 40403-40409, 2002.

[133] M. Rodríguez Pulido, P. Serrano, M. Sáiz, and E. MartínezSalas, "Foot-and-mouth disease virus infection induces proteolytic cleavage of PTB, eIF3a,b, and PABP RNA-binding proteins," Virology, vol. 364, no. 2, pp. 466-474, 2007.

[134] J. P. White, A. M. Cardenas, W. E. Marissen, and R. E. Lloyd, "Inhibition of cytoplasmic mRNA stress granule formation by a viral proteinase," Cell Host and Microbe, vol. 2, no. 5, pp. 295-305, 2007.

[135] V. Guerniou, R. Gillet, F. Berrée, B. Carboni, and B. Felden, "Targeted inhibition of the hepatitis C internal ribosomal entry site genomic RNA with oligonucleotide conjugates," Nucleic Acids Research, vol. 35, no. 20, pp. 6778-6787, 2007.
[136] C. Romero-López, R. Díaz-González, A. Barroso-del Jesus, and A. Berzal-Herranz, "Inhibition of hepatitis C virus replication and internal ribosome entry site-dependent translation by an RNA molecule," Journal of General Virology, vol. 90, no. 7, pp. 1659-1669, 2009.

[137] M. F. Rosas, E. Martínez-Salas, and F. Sobrino, "Stable expression of antisense RNAs targeted to the $5^{\prime}$ non-coding region confers heterotypic inhibition to foot-and-mouth disease virus infection," Journal of General Virology, vol. 84, no. 2, pp. 393-402, 2003.

[138] A. Vagnozzi, D. A. Stein, P. L. Iversen, and E. Rieder, "Inhibition of foot-and-mouth disease virus infections in cell cultures with antisense morpholino oligomers," Journal of Virology, vol. 81, no. 21, pp. 11669-11680, 2007. 

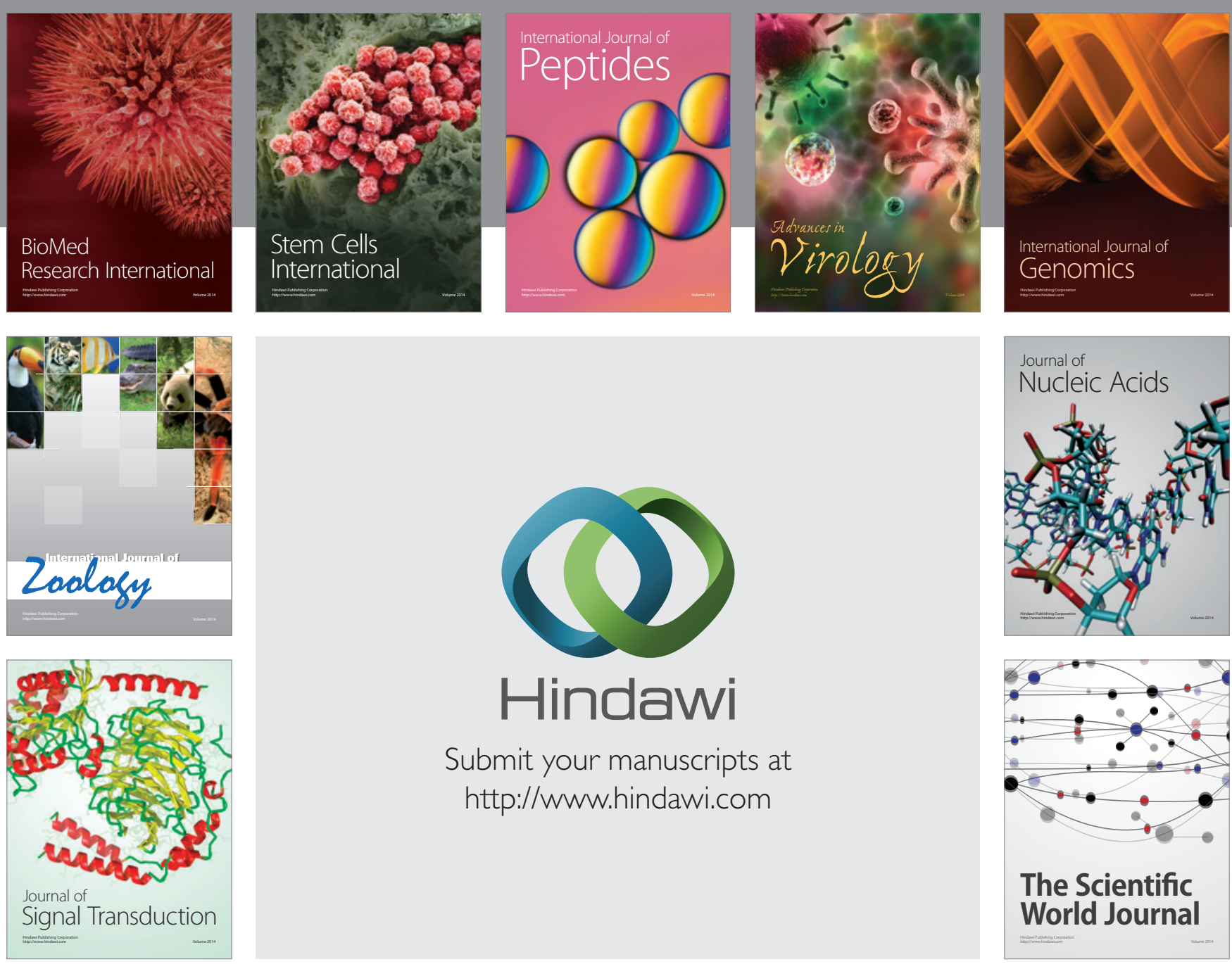

Submit your manuscripts at

http://www.hindawi.com
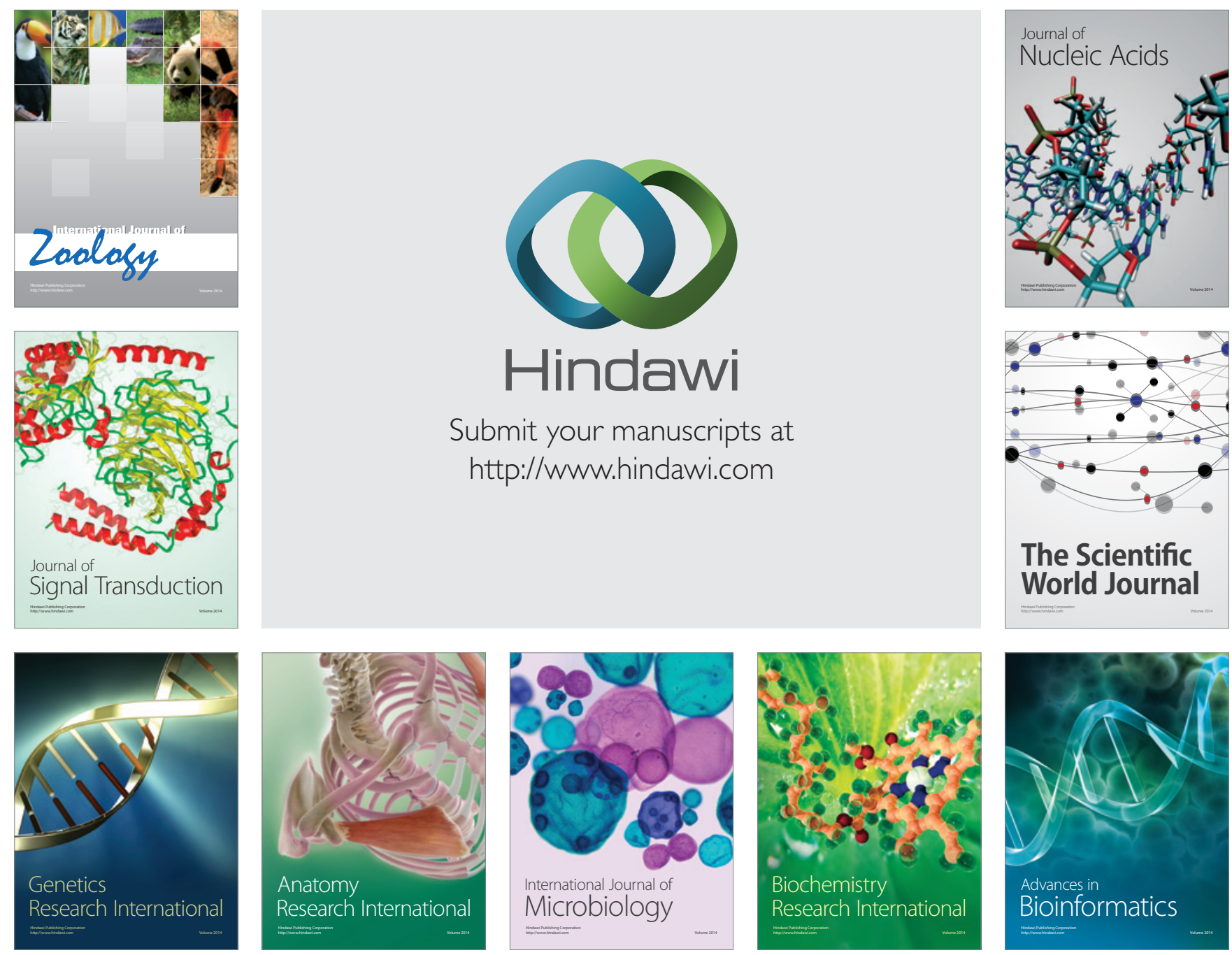

The Scientific World Journal
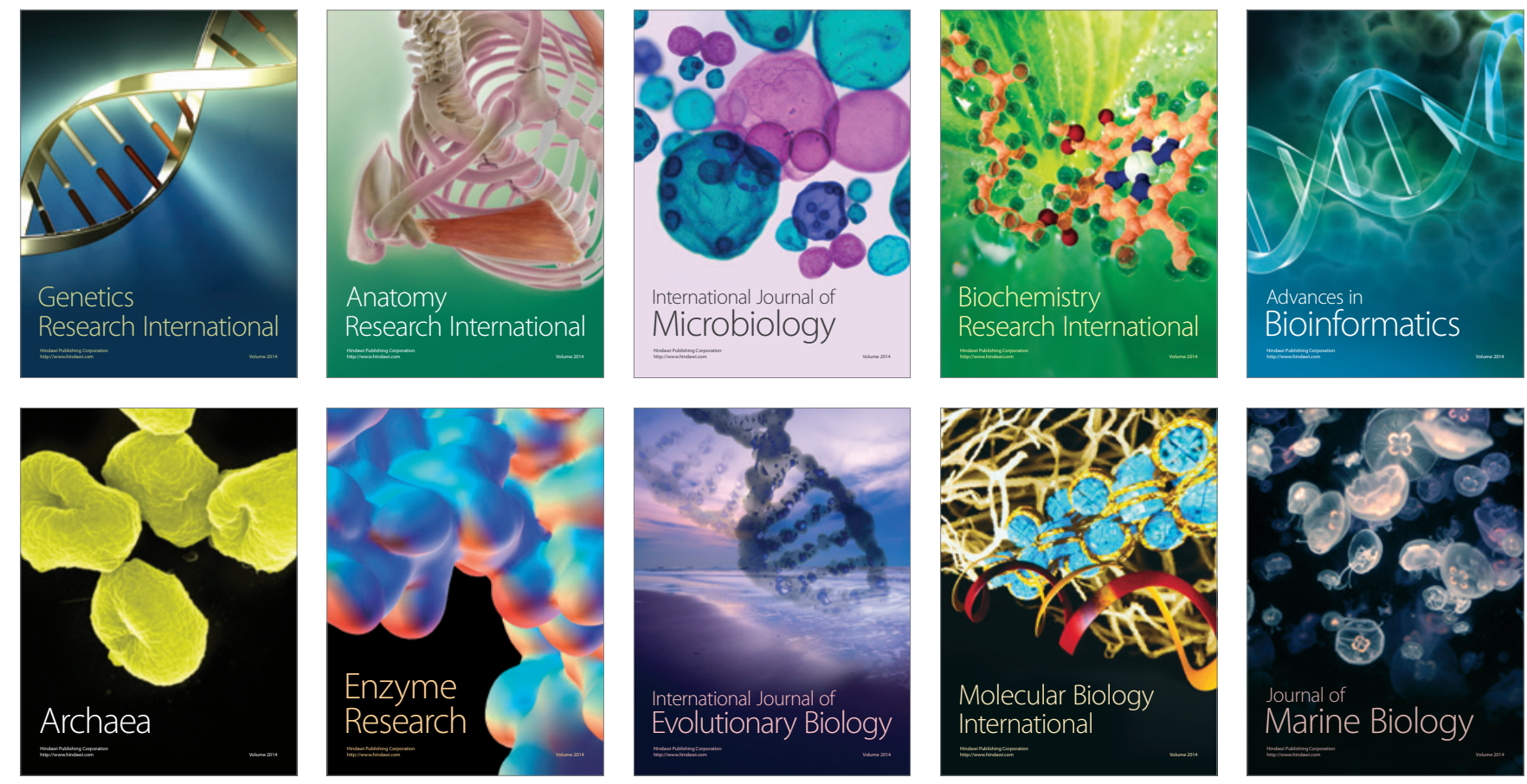